\title{
REFLEXÕES E IMPLICAÇÕES SOBRE A EDUCAÇÃO DE JOVENS E ADULTOS, O MUNDO DO TRABALHO E AS "NOVAS" COMPETÊNCIAS PARA OS JOVENS E ADULTOS TRABALHADORES
}

\author{
Madryracy Ferreira Coutinho Medeiros Ovídio ${ }^{1}$ \\ Antonio Amorim ${ }^{2}$
}

\section{RESUMO}

Este estudo é o resultado de uma pesquisa realizada com os alunos do Ensino Fundamental noturno da Educação de Jovens e Adultos (EJA), com o intuito de investigar o mundo do trabalho e as novas competências exigidas aos jovens e adultos trabalhadores. Nesse sentido, mediante pesquisa de campo realizadas na escola, levantamos a seguinte questão: A Educação de Jovens e Adultos deveria se enquadrar as novas competências exigidas no mundo do trabalho, uma "educação para o mercado de trabalho", uma preparação para o trabalho nos moldes previstos no modelo de produção capitalista, um trabalho que, para os trabalhadores é um trabalho marcado pela exploração, segmentação e exclusão? Desse modo, tratou-se de recolher e analisar a opinião de jovens e adultos trabalhadores, do Ensino Fundamental da Escola Maria Áurea Pimentel Ferreira (EMAPF), sobre as competências exigidas para ingressar e/ou permanecer no mundo do trabalho.

Palavras-chave: Educação de jovens e adultos. Competências. Mundo do trabalho.

\begin{abstract}
This study is the result of a survey conducted with the elementary students Nocturne of adult and youth education (EJA), in order to investigate the world of work and the new skills required for young and adult workers. In this sense, through field research carried out in school, we raised the question of the education of young people and Adults should fit the new skills required in the world of work, an "education to the labour market", a preparation for the work in the manner provided for in the model of capitalist production, a work that, for workers is a work marked by exploitation and alienation? Thus, it was collect and analyse the opinion of young and old workers, elementary school Maria Áurea Pimentel Ferreira (EMAPF), about the skills required to enter and/or remain in the world of work.
\end{abstract}

Keywords: adult and youth education; competences; World of t.

\footnotetext{
${ }^{1}$ Doutoranda do Programa de Pós-Graduação da Universidade do Estado da Bahia. Professora Orientadora de Pesquisa e Estágio do Departamento de Educação, UNEB/Campus XI/Serrinha. Docente da EJA da Escola Maria Áurea Pimentel Ferreira E-mail: madrycoutinho@ hotmail.com

${ }^{2}$ Doutor em Psicologia pela Universidade de Barcelona-Espanha. Professor Adjunto do Programa de PósGraduação MPEJA e do Departamento de Educação da Universidade Estadual da Bahia (UNEB). E-mail: antonioamorim52@gmail.com
} 


\section{Introdução}

Este estudo é o resultado de uma pesquisa realizada com os alunos do Ensino Fundamental noturno da Educação de Jovens e Adultos (EJA), da Escola Maria Áurea Pimentel Ferreira, da Rede Municipal de Ensino, do Município de Serrinha/BA. Aborda a nossa preocupação com a Educação de Jovens e Adultos, o mundo do trabalho e as competências exigidas aos jovens e adultos para ingressarem e/ou permanecerem no mundo do trabalho.

Diante dessa questão, o artigo foi concebido a partir do questionamento: A Educação de Jovens e Adultos deveria se enquadrar as competências exigidas no mundo do trabalho, uma "educação para o mercado de trabalho", uma preparação para o trabalho nos moldes previstos no modelo de produção capitalista, um trabalho que, para os trabalhadores é um trabalho marcado pela exploração, segmentação e exclusão?

Para responder a essas questões recorreu-se a pesquisa de campo na Escola Maria Áurea Pimentel Ferreira, buscou-se fundamentação nos referenciais de Deluiz (2001), Machado (1998), Movilla (2007), Ramos (2002), entre outros.

O objetivo foi investigar o mundo do trabalho e as competências exigidas aos jovens e adultos trabalhadores, a fim de requer que sejam repensados os perfis profissionais, os processos de formação nos âmbitos das escolas, a organização do sistema escolar e sua relação com o mundo do trabalho, a formação dos trabalhadores dentro e fora da escola.

A pesquisa de campo foi feita através de entrevistas semiestruturadas com um roteiro medianamente estruturado, com o objetivo de obter informações sobre a visão dos estudantes da Escola Maria Áurea Pimentel Ferreira (EMAPF) sobre as competências exigidas aos jovens e adultos para ingressarem e/ou permanecerem no mundo do trabalho e buscar compreender e descrever, a partir da perspectiva dos estudantes participantes, qual a contribuição da EJA para a sua inserção no mundo do trabalho. A escolha dos sujeitos participantes da pesquisa foi direcionada para garantir visões diferenciadas sobre o tema em questão.

Os principais resultados obtidos combinando as leituras e os estudos teóricos com a pesquisa de campo realizada na escola, referem-se às reais possibilidades e dificuldades de se construir democraticamente uma proposta que articule educação e trabalho, superando as contradições da sociedade capitalista e contribuindo para a reflexão e a autonomia dos estudantes trabalhadores em diferentes cenários do mundo do trabalho, intervindo nas relações 
de trabalho, de sociedade e contrapondo-se as ideias subordinadas a racionalidade econômica dominante.

O trabalho encontra-se estruturado em partes, sendo elas: o percurso da investigação, o mundo do trabalho e as competências exigidas para os trabalhadores, o paradigma da competência no contexto educacional - Os resultados do estudo de campo e, por último, as considerações finais.

\section{O percurso da investigação}

Para atender os objetivos da investigação nos cabe detalhar inicialmente o lócus onde foi realizada a pesquisa.

O município de Serrinha está localizado no semiárido baiano, distante cerca de 180 km da capital do estado. Possui população de 76.722 mil habitantes (IBGE, CENSO, 2010) que se divide em espaços rurais e urbanos. Conta com uma rede própria de ensino, formada por cento e quarenta e seis estabelecimentos de ensino, sendo cento e dezessete escolas municipais, onze estaduais e dezoitos privadas.

Escolhemos para a pesquisa uma escola dessa rede municipal: Escola Maria Áurea Pimentel Ferreira, que trabalha com a EJA desde a sua instalação em 2006, mantida pelo poder público municipal, administrada pela Secretaria de Educação e Cultura (SEC), nos termos da legislação em vigor. Tanto os estudantes, como a comunidade participam das atividades realizadas na EJA. É uma escola que se preocupa com os sujeitos da EJA, motivando-os para participarem do processo de construção do conhecimento. Com relação à estrutura física possui: 11 salas de aulas, laboratório de informática, laboratório de Ciências, biblioteca, uma quadra coberta. Na EJA o processo educativo é distribuído em etapas, ofertadas em cinco dias da semana, com duração média de três horas e, conta com quatro turmas do Ensino Fundamental II.

O corpo docente, pós-graduado, na sua maioria com mais de 15 anos de experiência na EJA, inspira confiança nos educandos e na comunidade. O grupo de servidores da escola na EJA é formado por: Uma diretora, uma vice-diretora, um secretário, um agente administrativo, um porteiro, dois vigilantes, uma merendeira, um professor e 06 professoras.

Os sujeitos da investigação, são jovens e adultos, na faixa etária entre 15 a 50 anos de idade, são pessoas que tiveram no seu passado um direito violado por não poder frequentar a escola na idade certa. A maioria dos estudantes são jovens, do sexo masculino, negros, de 
baixa renda e trabalhadores que vão direto do trabalho para a escola. Esses sujeitos possuem trabalho informal e atuam como: Funcionárias do lar, gesseiro, vendedor ambulante, diarista, pedreiro, ajudante de pedreiro, funcionários da fábrica de calçados e dos ateliês de calçados e almejam alcançarem melhores postos de trabalhos, sobretudo nas fábricas e ateliês de calçados presentes no bairro, buscando um futuro mais promissor, com melhor qualidade de vida para eles próprios e sua família. Essa realidade faz parte da conjuntura da EJA/Noturno e estabelece uma dinâmica singular na escola.

Para a coleta de dados, foi utilizada a entrevista que se tornou nosso principal instrumento no diálogo com os interlocutores. Ludke e André (1986), consideram a entrevista como uma conversa com objetivos e estratégias bem definidas, cuja natureza pode ser individual ou coletiva. De modo geral, as entrevistas podem ser estruturas, semiestruturadas ou nãoestruturadas. Optamos por realizar entrevistas semiestruturadas, pelo fato dessas permitirem o entrevistador esclarecer dados, ou seja, manter um diálogo com o entrevistado e deixá-los livres para desenvolverem as questões da maneira que desejarem. Dessa forma, apresentamos aos entrevistados questões previamente elaboradas, mas com reserva de espaço para conversa livre, respeitando o entrevistado, sua cultura e seus valores. A respeito do objetivo da entrevista, Minayo (2010, p. 64)), ressalta que "ela tem o objetivo de construir informações pertinentes para um objeto de pesquisa, e abordagem pelo entrevistador, de temas igualmente pertinentes com vistas a este objetivo". Portanto, ela demanda por parte do entrevistador uma capacidade de escuta atenta no tocante aos temas e ao universo de informações.

Resumidamente, dois momentos foram definidos para coleta de dados: Primeiramente, entrevistamos os estudantes jovens e, em segundo momento, entrevistamos os estudantes adultos, todos tiveram que responder as mesmas questões. Dividimos em dois grupos para que os mais experientes não influenciassem os mais jovens em suas respostas. Convém esclarecer que os estudantes jovens e os adultos em momento algum, verbalizaram ou insinuaram resistência quanto a concessão das entrevistas. Quanto a escolha dos estudantes jovens e adultos para realização das mesmas, optamos por selecionar os que já estavam trabalhando e tinham no mínimo um ano de experiência. Tivemos também a preocupação de ficarmos atentos ao sexo, para não incorrer no risco de selecionarmos predominantemente um sexo, em detrimento do outro. Os entrevistados serão identificados por EJ (Estudante jovem) 1... 5 e EA (Estudante Adulto)1...5, sempre que se utilizar as opiniões fornecidas nas entrevistas por eles, evitando-se, assim, identificações pessoais. 
As formas de registros incluíram gravações de áudio e notas de campo que foram negociadas com os entrevistados e autorizados por eles. Depois, transcrevemos os depoimentos para facilitar na interpretação dos dados. Quando de sua análise, procurou-se estabelecer comparações quanto as afirmações expressas verbalmente e as discussões atuais sobre o mundo do trabalho, as competências exigidas para os trabalhadores e o paradigma da competência no contexto educacional.

\section{O mundo do trabalho e as competências para os trabalhadores}

Nas últimas décadas a temática competência ganhou destaque num contexto de desestabilidade do Estado do bem-estar social e dos direitos sociais garantidos por este, como, saúde, emprego, estabilidade, educação, moradia, direitos trabalhistas e redução da regularidade das relações de trabalho. Para Ramos (2002, p. 253), "A ética profissional inspirada por essa noção baseia-se, então, na adaptação individual a essas mudanças(...)"

O mundo empresarial defende a ideia de que a posição ocupada no mercado de trabalho é determinada pela sua competência, apresentando a mesma como a oportunidade de inserção, permanência ou reinserção num mercado de trabalho em constante metamorfose.

Para Bourdieu e Wacquant (2004), surge um novo imperialismo simbólico com a utilização de termos como, globalização, flexibilidade, competência, exclusão, nova economia, entre outros com a pretensão de (re)construir o mundo a partir da lógica mercadológica.

No seio da sociedade a disputa pela hegemonia perpassa pela hegemonia no plano cultural e ideológico. Neste cenário, o discurso é um dispositivo essencial para emancipação ou para impor a dominação. Nessa perspectiva, cabe indagar: De onde surge a noção de competência? Está a serviço de quem? Que novas perspectivas introduzem nas relações sociais e no mundo do trabalho?

Noam Chomsky (1960), é responsável por introduzir na literatura o termo competência, ao fazer alusão à "capacidade e disposição para o desempenho e para interpretação", provocando uma alteração no enfoque comunicativo ao propor uma profunda renovação na linguística do texto ou discursiva. Foi a partir da década de 70, que o conceito passou a ser utilizado na área de gestão de recursos humanos, alicerçado em estudos do professor David Maccleland, quando estudava a necessidade do sucesso e a aflição do poder. Segundo Diaz e Movilla (2007), tenciona os problemas da seleção tradicional, fundamentada 
na avalição de habilidades intelectuais e opõe-se a esta, sugerindo o modelo alternativo de seleção por competência.

Há uma diversidade de interpretações do conceito, mas nas suas mais variadas acepções, pode-se dizer “ para que uma pessoa leve a cabo exitosamente, uma atividade laboral determinada, deve demonstrar na execução dessa atividade laboral, um desempenho eficiente, a partir de que a competência é algo real e demonstrado, o que não se pode confundir com uma potencialidade a demonstrar" (DIAZ; MOVILLA, 2007, p.48). Nessa direção, as correntes da Sociologia das Organizações e do Trabalho, as teorias políticas, corroboraram dando importância às questões do poder, da estratégia, do controle e a discussão sobre o mercado, sendo determinada de fato, por redes econômicas, sociais, políticas e indenitárias, da própria sociedade.

A partir de 1985, a noção de competência surge na literatura sociológica francesa, conduzida pela sociologia do trabalho no discurso de empresários, industriais, empregadores apreensivos com as mudanças recentes sucedidas no mundo do trabalho, sobretudo, com as ocorridas nos postos de trabalho, passando a ser objeto de estudo de economistas e sociólogos, anteriormente envolvidos com a noção de qualificação.

O termo competência, segundo Tomasi (2004), origina-se nos meios jurídicos e, restringindo-se a ele inicialmente, mas é também utilizado por outras profissões. Sobre as competências, o autor afirma que dizem respeito ao uso de técnicas definidas, usadas e adaptas as novas conjunturas, mesmo não sendo criadas pelo indivíduo. A competência está ligada a execução de tarefas, organizadas e que exige uma atividade intelectual. Os especialistas são os que realizam as tarefas, assim, o incompetente não possui o saber e o saber-fazer, ou os possui incompletamente.

Habitualmente, o conceito de competência, que é polissêmico, na grande maioria das vezes, é utilizado como sinônimo de qualificação. Contudo, Dubar (1998), Manfredi (1998), e Ramos (2002), expressam que competência e qualificação apresentam acepções e finalidades distintas.

A dimensão conceitual da qualificação refere-se à formação, portanto, ao nível de domínio dos conceitos e do conhecimento (Ramos, 2002). Compreendida por Aranha (2007), como o conjunto de conhecimentos e aptidões adquiridas pelo profissional para desempenhar uma atividade profissional.

No campo educacional, a qualificação constitui-se "uma base para pensar e construir a transmissão dos conhecimentos profissionais" (DUGUÉ, 2004, p. 21). É a partir dela que é estruturado "todo o ensino profissional, pela escola ou pela aprendizagem; é o pivô em torno 
do qual se ordenam os processos de aprendizagem" (id, 2004, p. 21). Como é possível notar, o discurso da competência e da qualificação vai sendo utilizado amplamente na educação e, mais especificamente nos processos de aprendizagens, tendo no ensino o seu fio condutor.

O profissional qualifica-se em múltiplos espaços como, escola, universidade, empresa sindicato e associação, buscando condições para exercer a atividade do trabalho, transformando-se em um importante capital em todo uso profissional. A qualificação torna-se alvo de severas críticas, a partir de 1970 e Degué (2004), destaca como uma das críticas a adaptação a forma de produção ao modelo Taylorista , enquanto na atualidade o mundo do trabalho não é estático e sim dinâmico, exigindo um novo tipo de mão de obra e um novo padrão de acumulação flexível de capital.

O discurso da competência e da qualificação, segundo Machado (1998), tem como sustentáculo a ideologia do pensamento liberal burguês, visto que, defende-se a ideia de que a colocação do indivíduo no mercado de trabalho é “(...) definida pelos seus méritos individuais, para os quais seriam determinantes a qualidade de seus atributos, a gama de seus conhecimentos e a eficácia real de suas capacidades pessoais" (MACHADO,1998, p. 4). Desse modo, as competências, não são reconhecidas como propriedades criadas e potencializadas socialmente, são vistas como naturais. Surgindo assim, a idolatria da competência que, "é a apologia do poder individual, mediante o qual os produtos da atividade humana aparecem como mágicas pois, se apresentam independentes das relações sociais" (MACHADO, 1998, p. 5).

\section{O paradigma da competência no contexto educacional: os resultados do estudo de campo}

A partir da década de 90, a noção de competência torna-se o alicerce da política educacional para reforma curricular da educação básica e da educação profissional no Brasil, realizadas através do suporte financeiro de organismos internacionais, como por exemplo, Organização das Nações Unidas para a Educação, a Ciência e a Cultura (UNESCO), Organização Internacional do trabalho (OIT), Banco Interamericano de Desenvolvimento (BID), Banco Internacional para Reconstrução e Desenvolvimento (BIRD), visando “articular e subordinar a produção educacional às necessidades estabelecidas pelo mundo do trabalho e a necessidade de estabelecer mecanismos de controle e avaliação da qualidade dos serviços educacionais" (DELUIZ, 2001, p. 6). Assim, a noção de competência, passa a ser considerada elemento da educação e, é ponto central na organização curricular no Brasil, 
objetivando a organização dos processos de ensino e aprendizagem nas escolas em função do desenvolvimento das competências, acreditando que o uso da noção de competência será capaz de possibilitar o encontro entre o trabalho e os processos formativos.

Para a organização curricular através do paradigma das competências, faz-se necessário:

Investigação dos processos de trabalho para a identificação de perfis profissionais de conclusão; definição dos blocos de competências profissionais básicas, gerais e específicas relacionados aos perfis identificados; desenho da estrutura do currículo, em geral flexível e modularizado; definição dos itinerários profissionais com critérios de acesso aos módulos e ao curso; definição das estratégias de aprendizagem - prática pedagógica interdisciplinar e contextualizada, processo centrado na aprendizagem do aluno, individualização dos percursos de formação, construção significativa do conhecimento, seleção de situações de aprendizagem baseadas na pedagogia de projetos e situações-problema; e definição do processo de avaliação da aprendizagem (DELUIZ, 2001, p.10).

Por outro lado, estas indicações ficarão no campo abstrato, sem um sentido mais concreto e explicito, caso os Gestores, Coordenadores e Professores não levarem em consideração as formas de como serão efetivados estes indicadores.

Considerando que a partir da subordinação da educação às exigências estabelecidas pelo mundo do trabalho, estaria mais próxima a relação entre o mundo do trabalho e a escola. Analisamos a respeito de como a Escola Maria Áurea Pimentel (MAFP) propicia conhecimento aos seus alunos para atuarem no mundo do trabalho? Visto que, nas suas proximidades há fábricas e ateliês de calçados que empregam muitos dos estudantes da EJA. Nas respostas de alguns jovens e adultos entrevistados, as informações contidas nos livros e trabalhadas pelos professores e professoras não promovem o encontro entre o trabalho e a escola, embora alguns professores realizem algumas reflexões críticas envolvendo a temática trabalho. Para um estudante adulto, "os professores é que são muito críticos, e realizam algumas reflexões mais amplas sobre o mundo do trabalho" (EA3). Outros adultos entrevistados, sugerem que a escola deveria realizar atividades vinculadas as fábricas, ateliês de calçados e a rede comercial existente no bairro, aproximando mais a escola do mundo do trabalho deles. Para EA5, "a escola precisaria se aproximar mais da realidade dos estudantes da EJA, do seu jeito de viver e do seu mundo do trabalho".

Diante das falas dos estudantes, fica claro o discurso que defendem e cobram a ligação da escola com as demandas imediatas do mercado de trabalho. Entretanto, precisamos fazer uma interpretação cuidadosa a respeito dos desígnios a que deve servir o sistema escolar, que privilegia sua submissão à função reprodutora da força de trabalho para o mercado, de acordo 
com as necessidades destes. Portanto, cabe à escola promover a crítica proposta pela sociologia da educação de viés Marxista, evidenciando a relação entre escola e o modo de produção capitalista, o caráter de classe no discurso de que a escola deve preparar para o mercado de trabalho, um discurso representativo dos interesses da burguesia brasileira e de suas frações.

Nesta direção, parece pertinente ainda elencar as características básicas presentes nas relações sociais de produção e de trabalho na sociedade capitalista: A promoção da alienação do trabalhador no processo de trabalho e a exploração da mais valia dos trabalhadores pelos proprietários dos meios de produção e dos meios de organização do trabalho. Vale ressaltar, ainda, que essas características, coloca o trabalhador nos processos de trabalho numa posição de subordinado, subalterno, reduzindo as possibilidades de os trabalhadores atuarem de forma autônoma e independente.

Buscando compreender o grau de "autonomia" do trabalhador nas relações de trabalho dos estudantes jovens e adultos da EJA, nas fábricas e ateliês de calçados, perguntamos: Como é desenvolvido o trabalho nas fábricas e qual a forma de participação dos trabalhadores nas etapas de produção? De acordo com um estudante jovem, "o trabalho na fábrica é muito cansativo, chegam a trabalhar de seis a oito horas, os horários são bem rígidos, durante a produção não podem conversar e não decidem nada... Apenas executam as ações determinadas pelos seus chefes, como: cortar, costurar, colar, encaixotar, entre outras" (EJ1). Para o estudante adulto, "a fábrica não paga bem pelos serviços que eles realizam, mas infelizmente como o município não oferece outro emprego tem que ficar nesse que mais parece um quartel, pelas exigências e rigidez" (EA4). Uma estudante adulta, revelou que:

Chega a ser humilhante o trabalho na fábrica, pois até quando se vai ao banheiro e demora muito o supervisor fica batendo na porta para que a gente volte para a produção, não temos direito a quase nada. Temos que executar as tarefas ordenadas pela chefia sem poder sequer conversar ou opinar sobre o melhor meio de produzir. Eles só se preocupam em bater as metas, em ganhar dinheiro as nossas custas. (EA 1).

Os recortes apresentados evidenciam que os estudantes jovens e adultos ocupam postos de trabalho subordinados, cujos ocupantes não têm nenhum controle, nem poder de decisão sobre o produto de seu trabalho e nem sobre o seu processo. Não possui também nenhum grau de liberdade, dentro dos limites inflexíveis marcados pelo horário, pela 
adequação às relações hierárquicas, pelo respeito à autoridade e pelas tarefas a cumprir incorporadas a uma sequência mecânica.

Questionados sobre o porquê dos estudantes trabalhadores não ocuparem outros postos de trabalhos na fábrica e ateliês de calçados, como: Supervisor, Coordenador de produção, entre outros cargos de chefia, explicaram: "Acredito que falta competência para assumir estes cargos, visto que não sabemos fazer o que eles fazem" (EA2). "Por não ter competência para desempenhar essas tarefas" (EJ2) e para EJ4, "por não serem preparados na escola para saber assumir essas tarefas na fábrica”.

Os relatos acima, citam muito a ausência de competência para assumir outros postos de trabalho. Buscando compreender o sentido da competência para os jovens e adultos, questionamos: Qual o significado da competência para você? Alguns jovens e adultos afirmaram: "A pessoa é competente quando tem um conhecimento profundo sobre a profissão e executar com eficiência esta profissão" (EJA 2). "A pessoa é competente quando realiza bem as atividades no seu trabalho" (EJ5). "É competente quando desempenha bem suas funções no trabalho" (EA4).

Observa-se que os estudantes não conseguiram apresentar a noção de competência. Eles apresentaram a opinião e auto percepção do que é ser um profissional competente, sendo entendido como algo centrado no indivíduo e adquirido através de esforço pessoal. Os jovens e adultos trabalhadores, acreditam que a competência está relacionada à ação e que a posição no mercado de trabalho pelo indivíduo é definida pelos seus méritos. Na verdade, apesar de não apresentarem claramente a noção de competência, evidenciam que valorizam a subjetividade do indivíduo e destaca o saber-ser. Entretanto, não percebem que a meritocracia contribui para a cooptação do trabalhador e o enfraquecimento dos laços coletivos.

Nesse sentido, não reconhecem que o discurso da competência está ancorado na ideologia do sistema capitalista, por disseminar que o lugar ocupado no mercado de trabalho pelo indivíduo é definido “ (...) pelos seus méritos individuais, para os quais seriam determinantes a qualidade de seus atributos, a gama de seus conhecimentos e a eficácia real de suas capacidades pessoais" (MACHADO,1998, p. 4). Assim, os jovens e adultos trabalhadores alimentam o culto a competência, que "é a apologia do poder individual, mediante o qual os produtos da atividade humana aparecem como mágicas pois, se apresentam independentes das relações sociais" (MACHADO, 1998, p. 5).

A pesquisa realizada não deixa dúvidas de que o termo competência é visto como uma demanda do mercado, mas também, como à capacidade de mérito pessoal de cada sujeito buscar uma posição no mercado de trabalho, submetendo-se ao modelo neoliberal. Esta 
concepção deixa claro que, na perspectiva neoliberal a formação para o mundo do trabalho perde qualquer traço emancipatório e criativo para se adequar as exigências mercadológicas, impondo esta (re)estruturação as instituições, aos currículos e a formação dos jovens e adultos.

\section{Considerações finais e provisórias}

A medida que eram coletados os dados, o cotidiano escolar passou a ser olhado atentamente e a escuta aos estudantes sobre o mundo do trabalho e a sua relação com o contexto escolar mais priorizada. Durante a realização da pesquisa buscou-se compreender “ A Educação de Jovens e Adultos deveria se enquadrar as novas competências exigidas no mundo do trabalho, uma 'educação para o mercado de trabalho', uma preparação para o trabalho nos moldes previstos no modelo de produção capitalista de alienação e exploração?

É importante evidenciar que o trabalho é uma atividade relevante do ponto de vista da reprodução das relações sociais humanas, reconhecemos que é necessário "educar para o trabalho" os jovens e adultos. Mas, é preciso ter clareza de que tipo de "trabalho" é proposto em cada instituição escolar, a serviço de quem, quais interesses representam junto ao sistema escolar. Assim, como discutir porque a inclusão de suas propostas para escola, por que mudar o currículo e os conteúdos disciplinares, tendo em vista que é para atender as demandas mercadológicas, do modelo capitalista com a estruturação do trabalho marcado pela exploração, pela alienação, segmentação e da exclusão, reduzindo a educação as necessidades ao atendimento do mercado de trabalho e a lógica empresarial.

Os relatos apresentados na pesquisa reforçam que os educandos da EJA, cobram e tem expectativas que a escola trabalhe tendo como paradigma a racionalidade e a eficácia, considerando a forma capitalista de organização do trabalho para o mercado, adequando a proposta escolar as necessidades destes mercados. Além das expectativas dos estudantes, a escola e especialmente a EJA, se depara com a exigência do mercado por uma educação que forme sujeitos "dócil, submisso à autoridade e eficiente na resposta às ordens e às tarefas". (ENGUITA, 1989, p. 144); dotados de multifuncionalidades, disciplina e alta produtividade. Ou seja, a formação do sujeito para o processo capitalista, para o trabalho alienado. Portanto, espera-se que por meio das práticas escolares, os jovens e adultos da classe trabalhadora sejam preparados para inserir-se de forma não conflitiva no mundo da produção e do trabalho em geral (ENGUITA, 1989).

A pesquisa revela-nos que os riscos de atender a estas demandas é transformar a EJA em um ensino mecanicista, determinista, imediatista e produtivista, capaz de atender a 
formação de um perfil de mão de obra. Entretanto, o mercado de trabalho é dinâmico por causa da rotação do capital e tende a mudar suas exigências para atender a demandas sociais, políticas, culturais e produtivas, tornando superadas competências tidas como necessárias.

Os estudos apontam que a escola deve buscar outras formas de articulação entre educação e trabalho, indo além do mero atendimento das necessidades de reprodução das relações de produção do modelo capitalista e das exigências do mercado de trabalho. É preciso que a escola prepare os jovens e adultos para lutar pela crescente transformação das bases econômicas, políticas, sociais e culturais para construção de uma nova ordem social, superando as contradições da sociedade capitalista e contribuindo para a reflexão e a autonomia dos estudantes trabalhadores em diferentes cenários do mundo do trabalho, intervindo nas relações de trabalho, de sociedade e contrapondo-se as ideias subordinadas a racionalidade econômica dominante.

Observou-se, também que, o novo desafio no cenário educacional brasileiro configurase na articulação entre educação, trabalho, formação profissional e EJA, evidenciando que essa problemática necessita de estudos e debates para "empoderar", mover gestores, professores e estudantes trabalhadores para aprendizados escolares não serem traçados para atender as intenções da classe dominante do capital.

\section{REFERÊNCIAS}

ARANHA, A. Qualificação do trabalhador. Dicionário da educação profissional: núcleo de estudos sobre trabalho e educação. Belo Horizonte: Fidalgo e Machado, 2000.

BOURDIEU, Pierre; WACQUANT, Löic. O imperialismo da razão neoliberal. Revista Possibilidades. Ano 1, n. 1,p. 24-28, jul/set. 2004. Tradução por Teresa Van Acker. Disponível em : <httt://www. npmueg.ubbi.com.br>. Acesso em 15 de maio de 2016.

DESLANDES, S. F.; NETO, O. C.; GOMES, R.; MINAYO, M. C. S. Pesquisa social: teoria, método e criatividade. Petrópolis, RJ: Vozes, 2010.

DELUIZ, N. O modelo de competências profissionais no mundo do trabalho e na educação: implicações para o currículo. Boletim Técnico do Senac, Rio de Janeiro, v. 27, n. 3, set/dez 2001.

DIAZ, Rafael Tejeda \& MOVILLA, Sílvia Campos. Formación por competências professionales en las Universidades. IN: Trabalho e Educação. Revista do Núcleo de Estudos sobre Trabalho e Educação (NETE). FAE/UFMG. Jan/jun. Vol 16 no. 1, FAE/UFMG, Belo Horizonte, 2007. 
DUBAR, C. A sociologia do trabalho frente à qualificação e à competência. Educação $\boldsymbol{e}$ Sociedade. v. 19, n. 64, Campinas, set. 1998.

DUGÜÉ, Elisabeth. A Lógica da competência: o retorno do passado. IN: TOMASI, Antônio (Org.). Da Qualificação à competência: pensando o século XXI. Campinas, SP: Papirus, 2004.

ENGUITA, Mariano Fernández. A face oculta da escola: educação e trabalho no capitalismo. Porto Alegre: Artes Médicas, 1989.

LÜDKE, Menga; ANDRÉ, Marli E. D. A. Pesquisa em educação: abordagens qualitativas. São Paulo: EPU, 1986.

MACHADO, Lucília Regina de Souza. Educação básica, empregabilidade e competência. Revista trabalho e educação. Belo Horizonte, nº 3, jan/jul, 1998.

MANFRENDI, S. M. Trabalho, qualificação e competência profissional das dimensões conceituais e políticas. Educação e Sociedade, v. 19, n. 64, Campinas, set. 1998.

RAMOS, Marise Nogueira. A pedagogia das competências: autonomia ou adaptação? 2. ed. São Paulo: Cortez, 2002.

TOMASI, Antônio. Qualificação ou Competência. IN: TOMASI, Antônio (Org.). Da Qualificação à competência: pensando o século XXI. Campinas, SP: Papirus, 2004. 